\title{
Rapid and Sensitive Determination of Lipid Oxidation Using the Reagent Kit Based on Spectrophotometry (FOODLABfat System)
}

\author{
Chang Woo Kwon, ${ }^{1}$ Kyung-Min Park, ${ }^{1}$ Jeong Woong Park, ${ }^{2}$ JaeHwan Lee, ${ }^{3}$ \\ Seung Jun Choi, ${ }^{4}$ and Pahn-Shick Chang ${ }^{1,5}$ \\ ${ }^{1}$ Department of Agricultural Biotechnology, Seoul National University, Seoul 151-921, Republic of Korea \\ ${ }^{2}$ Department of Technology and Research, Sanigen Co., Ltd., Gwacheon 427-070, Republic of Korea \\ ${ }^{3}$ Department of Food Science and Biotechnology, Sungkyunkwan University, Suwon 440-746, Republic of Korea \\ ${ }^{4}$ Department of Food Science and Technology and Department of Interdisciplinary Bio IT Materials, \\ Seoul National University of Science and Technology, Seoul 139-743, Republic of Korea \\ ${ }^{5}$ Center for Food and Bioconvergence and Research Institute of Agriculture and Life Sciences, Seoul National University, \\ Seoul 151-742, Republic of Korea \\ Correspondence should be addressed to Seung Jun Choi; stylishchoi@gmail.com and Pahn-Shick Chang; pschang@snu.ac.kr
}

Received 7 October 2016; Accepted 16 November 2016

Academic Editor: Aminah Abdullah

Copyright (C) 2016 Chang Woo Kwon et al. This is an open access article distributed under the Creative Commons Attribution License, which permits unrestricted use, distribution, and reproduction in any medium, provided the original work is properly cited.

The reliability and availability of FOODLABfat system for determining acid value (AV) and peroxide value (POV) were assessed during the hydrolytic rancidification and lipid oxidation of edible oils. This reagent kit based on spectrophotometry was compared to the official methods (ISO 660 and 3960 protocols) based on manual titration employing the standard mixture for the simulated oxidation models and edible oils during the thermally induced oxidation at $180^{\circ} \mathrm{C}$. The linear regression line of standard mixture and the significant difference of thermally oxidized time course study determined between them showed high correlations $\left(R^{2}=\right.$ 0.998 and $p<0.05$ ) in both AVs and POVs. Considering ISO protocols with a probability of human error in manual titration, the rapidness and simplicity of the reagent kit based on spectrophotometry make it a promising alternative to monitor the lipid oxidation of edible oils and lipid-containing foods.

\section{Introduction}

Lipid oxidation is a major deteriorative reaction of edible oils and lipid-containing foods, leading to the generation of rancid odors and off-flavors, nutritional losses, and the consequent decrease of shelf-life $[1,2]$. Furthermore, this undesirable deterioration is responsible for the formation of cholesterol oxides and the deposition of atherosclerotic plaque, which increases in a risk for cardiovascular diseases $[3,4]$. During the entire process from manufacture and storage to continued use and ultimate intake, the monitoring of lipid oxidation is indispensable to control the aforementioned concerns (i.e., sensory acceptability and safety hazards for human consumption).
Edible oils consisting of abundant polyunsaturated fatty acids are susceptible to auto-, thermal-, and/or photosensitized oxidations and the degree of lipid oxidation can be determined using a variety of methodologies which quantify the oxidized intermediates and products during specific phases of the reaction [5]. Among the methodologies, the acid value $(\mathrm{AV})$ and peroxide value (POV) have been adopted as primary indicators which could assess hydrolytic rancidity and hydroperoxides formation of edible oils at the initial phases of lipid oxidation [6].

The official methods for the determination of $\mathrm{AV}$ and POV are ISO 660 and ISO 3690, respectively, specified by International Standards Organization (ISO) $[7,8]$. The ISO protocols have extensively been used for decades and there is 
no doubt about reliability and validity. However, it is plausible that there may be human error and a significant difference in the measured values by different operators. This is due to the fact that the ISO protocols based on manual titration need to determine the endpoint (e.g., color development or disappearance) with the naked eye. Moreover, the protocols have been considered to be time-consuming and laborintensive analytical procedures because of the preparation of specific reagents and manual titration $[9,10]$.

Recently, as an alternative approach, the reagent kit based on spectrophotometry (e.g., FOODLABfat system) was developed and commercially available for the determination of AV and POV of edible oils, which has garnered attention from a wide range of potential users. Even though this reagent kit analyzer could provide simple procedure and rapid detection without disadvantages of the conventional methods, there has been insufficient evidence to validate the reliability and reproducibility of the reagent kit.

In view of this observation, we attempted to confirm the correlation of measured values between the ISO protocols and the reagent kit in terms of AV and POV employing both standard mixtures for the simulated models and edible oils for the practical models by thermally induced oxidation (e.g., deep-fat frying).

\section{Materials and Methods}

2.1. Materials. Canola, palm, and soybean oils were purchased from a local grocery market located in Seoul, Republic of Korea. Olive oil (highly refined, low acidity (expressed as oleic acid, of not more than $0.3 \%$ )) was purchased from Sigma-Aldrich (St. Louis, MO, USA). Oleic acid and a tertbutyl hydroperoxide solution (5.0-6.0 $\mathrm{M}$ in decane), used as standard compounds for AV and POV analyses, respectively, were also purchased from Sigma-Aldrich. The spectrophotometric analyzer (FOODLABfat) and its $\mathrm{AV}$ and POV reagent kit were built and formulated by CDR Mediared Co., Ltd. (Florence, Tuscany, Italy), respectively, and they were gifted form CDR Mediared. Co. Ltd. All other reagents were of analytical grade and were used without further purification.

\subsection{Preparation of Standard Mixture for the Simulated Models.} Oleic acid of $0.02-0.30 \mathrm{~g}$ and tert-butyl hydroperoxide solution of $0.1-0.6 \mathrm{~g}$ were filled with olive oil up to $20 \mathrm{~g}$ to prepare $0.1-1.5 \%$ standard mixture for AV and $0.05-0.30 \%$ standard mixture for POV, respectively.

\subsection{Thermally Induced Oxidation of Commercialized Edible} Oils. One gram of oil samples was put in 24 glass vials (27 $\mathrm{mm}$ inner diameter), which were exposed to the air. Because palm oil is semisolid at ambient temperature; it liquefied at melting point (approximately $40^{\circ} \mathrm{C}$ ) before distribution into vials. To simulate the deep-fat frying process, vials containing oil samples were heated to $180^{\circ} \mathrm{C}$ in a dry oven without stirring. At predetermined intervals, pooling was conducted by merging thermally oxidized oils in glass vials into a single pooling glass vial to perform further analysis.
2.4. AV Determination. AV was determined according to ISO 660 . An appropriate amount (10-20 g) of oil, depending on the predetermined free fatty acid content, was dissolved in $100 \mathrm{~mL}$ of an ethanol/ether mixture $(1: 1, \mathrm{v} / \mathrm{v})$. This solution was gently mixed and $300 \mu \mathrm{L}$ of $1 \%$ phenolphthalein solution was added as an indicator. Then, the mixture was titrated with $0.1 \mathrm{M}$ ethanolic potassium hydroxide until its color changed to a light pink. The AV is expressed as milligrams of potassium hydroxide required to neutralize the free fatty acids present in $1 \mathrm{~g}$ of oil. In the case of FOODLABfat, free fatty acid levels were determined spectrophotometrically and then expressed as a percentage by mass based on the oleic acid content. Appropriate aliquots of oil $(2.5$ and $1.0 \mu \mathrm{L}$ for analyzing the $0.03-1.10$ and $0.08-3.50 \%$ oleic acid ranges, resp.) were added to the $\mathrm{AV}$ reagent kit containing phenolphthalein derivatives and potassium hydroxide dissolved in ethanol/ether mixture and incubated at $37^{\circ} \mathrm{C}$ for $3 \mathrm{~min}$. The resulting solution was well mixed, and its absorbance was measured at $630 \mathrm{~nm}$. The AV was calculated using a preplotted calibration curve.

2.5. POV Determination. POV was determined according to the protocol from ISO 3960. The ISO 3960 protocol was as follows: one gram of oil was dissolved in a $50 \mathrm{~mL}$ mixture of acetic acid and isooctane $(3: 2, \mathrm{v} / \mathrm{v})$ followed by the addition of $0.5 \mathrm{~mL}$ freshly prepared saturated potassium iodide solution. The solution was gently mixed, incubated for $10 \mathrm{~min}$ in the dark, and then diluted with $100 \mathrm{~mL}$ distilled water. Finally, the mixture was slowly titrated with $0.01 \mathrm{~N}$ sodium thiosulfate in the presence of a starch solution $(1 \%, 1 \mathrm{~mL})$ until the dark blue color disappeared. POV was expressed in mmole of peroxide (or active oxygen) per $\mathrm{kg}$ of oil $\left(\mathrm{meqO}_{2} \mathrm{~kg}^{-1}\right)$. In the case of FOODLABfat, appropriate aliquots of oil (5.0 and $2.5 \mu \mathrm{L}$ for analyzing the 0.3-25.0 and $1.0-50.0 \mathrm{meqO}_{2} \mathrm{~kg}^{-1}$ peroxide ranges, resp.) and $10 \mu \mathrm{L}$ of a redox solution containing iron(II) chloride were added to the methanol/1-decanol $/ n$-hexane $(3: 2: 1, \mathrm{v} / \mathrm{v} / \mathrm{v})$ mixture containing ammonium thiocyanate and incubated at $37^{\circ} \mathrm{C}$ for $3 \mathrm{~min}$. Then, the solution was well mixed and the absorbance was measured at $505 \mathrm{~nm}$. Like AV measurement, the POV was calculated using a preplotted calibration curve.

2.6. Statistical Analysis. The experiments were conducted in triplicate, and the mean values and standard deviations are reported. The results from AV and POV were analyzed using Student's $t$-test. All statistical analyses were accomplished using the SPSS software (version 20.0, IBM Corp., Armonk, NY, USA).

\section{Results and Discussion}

3.1. AV and POV in the Simulated Models. The official method for AV measurement is based on the acid-base titration techniques in nonaqueous solvents. The oil sample is dissolved in the organic solvent containing phenolphthalein as a color indicator. Then, this organic solution is titrated with an ethanolic potassium hydroxide solution. When an oil sample containing free fatty acids to some extent is dissolved 


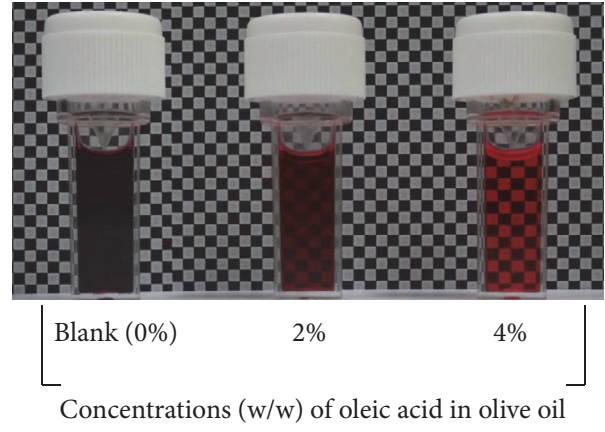

FIGURE 1: Changes in the color intensity of AV reagent kit with the increase in oleic acids of standard mixtures for the simulated oxidation model.

in the organic solvent, the $\mathrm{pH}$ of organic solvent could be acidic. Then, because phenolphthalein is colorless in acidic solutions, the organic solution is transparent. If potassium hydroxide is added into the organic solution and all of the carboxylic groups of the free fatty acids are neutralized, the color of the organic solution turns pink because it is basic. Therefore, by determining the endpoint at which the color turns pink, the AV could be measured by calculating the volume of potassium hydroxide consumed to neutralize the free fatty acids present in oil sample. While the official method determines AV by judging the endpoint, FOODLABfat determines the AV by monitoring the change in the intensity of a chromogen, absorbed at $630 \mathrm{~nm}$, dependent on an amount of fatty acids in the oil sample. The color changes of the AV reagent kit dependent on the amount of fatty acids are shown in Figure 1. The color intensity decrease, read at $630 \mathrm{~nm}$, was proportional to the concentration of free fatty acids in the standard mixture. The mechanism for the absorbance reduction at $630 \mathrm{~nm}$ is based on host-guest chemistry. A phenolphthalein derivative as a host freely exists in the AV reagent kit and it could be alkaline condition because of the presence of potassium hydroxide. When the $\mathrm{pH}$ drops due to the addition of free fatty acid as a guest, a guest molecule could complex with a host molecule, and this complex could have weak or no absorbance at $630 \mathrm{~nm}$. To confirm the mechanism above, the $\mathrm{pH}$ of the $\mathrm{AV}$ reagent kit was dropped by adding organic (butyric or citric acid) or inorganic (hydrochloric acid) acid instead of fatty acid (oleic acid in this study), followed by the absorbance reading at $630 \mathrm{~nm}$. Because butyric, citric, and hydrochloric acids have different numbers of acidic protons, their added amounts were determined by considering the final concentration of acidic protons in the AV reagent kit. Interestingly, when any acids with the same number of acidic protons were added to the $\mathrm{AV}$ reagent kit, they showed very similar absorbance at $630 \mathrm{~nm}$ (data not shown). This result indicates that the reduction of absorbance at $630 \mathrm{~nm}$ was independent of the molecular structure and properties.

The official method for POV determination is based on an iodometric titration technique. During POV determination with the official method, the peroxides in the oil sample convert $\mathrm{I}^{-}$to $\mathrm{I}_{2}$ by reduction. $\mathrm{I}_{2}$ complexes with starch,

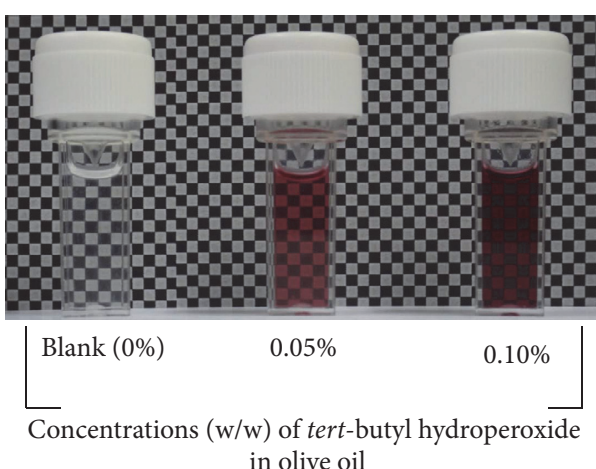

FIgURE 2: The formation of chromogen in POV reagent kit with the increase in tert-butyl hydroperoxides of standard mixtures for the simulated oxidation model.

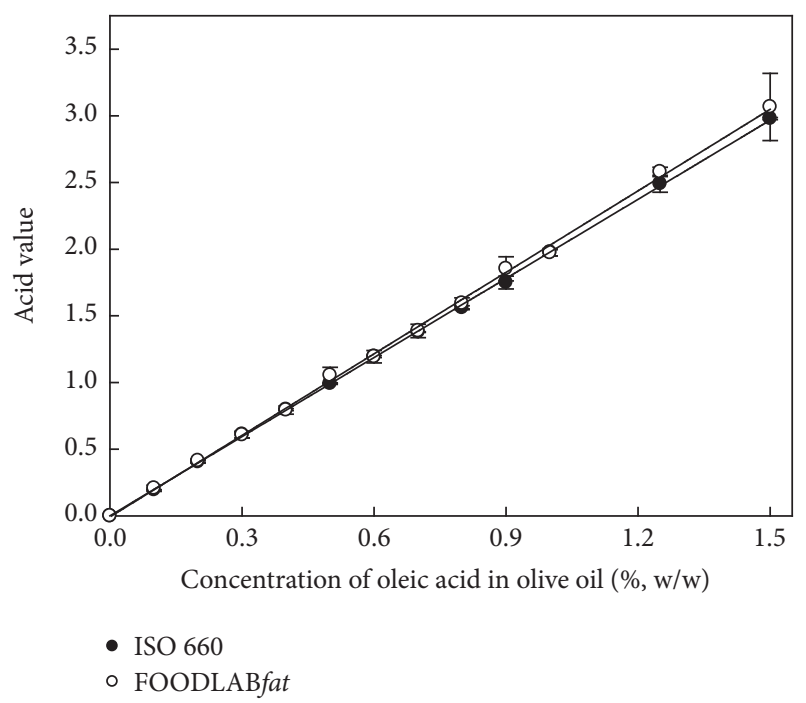

FIGURE 3: The comparison of AVs in the simulated oxidation model, determined according to the official method (ISO 660 protocol) and $\mathrm{AV}$ reagent kit of FOODLABfat.

resulting in the development of a dark blue color. Then, when $\mathrm{I}_{2}$ is oxidized by thiosulfate, the dark blue color disappears. Therefore, in the official method, the amount of consumed sodium thiosulfate solution can be directly related to the amount of hydroperoxides in the oil sample. However, the FOODLABfat is based on a modification of the reference method IDF 74 (ISO 3976) (Figure 2) [11].

Changes in AVs obtained from FOODLABfat and the official method (ISO 660) are shown in Figure 3. Oleic acid dissolved in olive oil was used as a standard compound for $\mathrm{AV}$ analysis. The initial AV of olive oil was approximately 0.1. Excellent agreement could be found among the results from ISO 660 and FOODLABfat for concentrations up to $1.5 \%$ oleic acid (3.0 of AV). Changes in POVs obtained from FOODLABfat and ISO 3960 are shown in Figure 4. tert-Butyl hydroperoxide dissolved in olive oil was used as a standard compound for POV analysis. The initial POV of olive oil was approximately 12.0. Strong agreement was observed among 


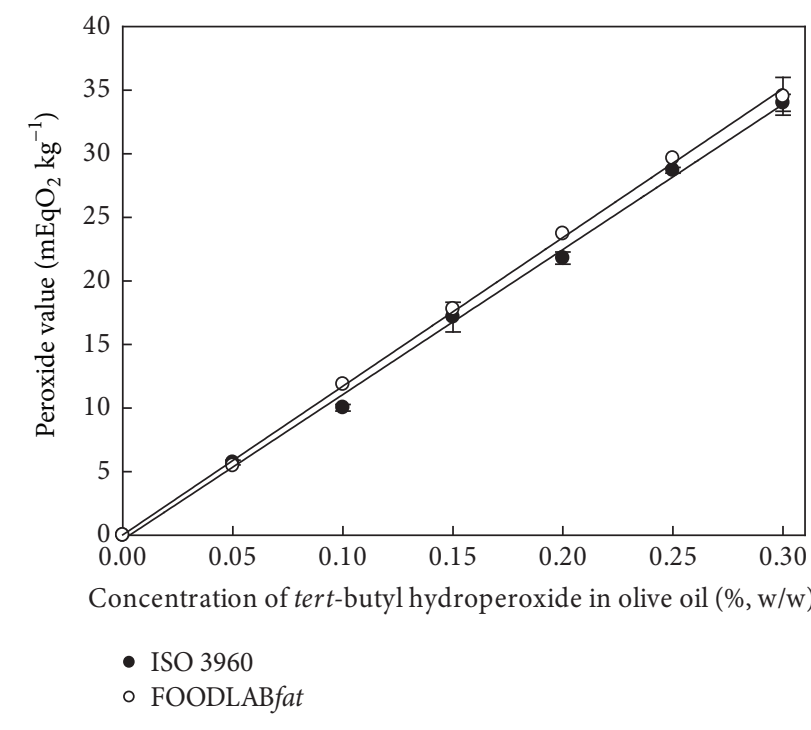

FIgURE 4: The comparison of POVs in the simulated oxidation model, determined according to the official method (ISO 3960 protocol) and POV reagent kit of FOODLABfat.

the results from ISO 3960 and the FOODLABfat for POV ranging from 0 to 50.0 .

3.2. Practical Validation Using Commercialized Edible Oils. General fatty acid compositions of canola, olive, palm, and soybean oils used in this study are presented in Table S1 (Supplementary Data, in Supplementary Material available online at http://dx.doi.org/10.1155/2016/1468743) [12]. Apart from palm oil, the major fatty acids were oleic $(60.1,23.9$, 72.5, and $39.1 \%$ for canola, soybean, olive, and palm oils, resp.) and linoleic (21.5, 52.1, 9.4, and 10.2 for canola, soybean, olive, and palm oils, resp.) acids. In particular, the major fatty acid in palm oil was palmitic acid (43.8\%). The purpose of employing these various oils is to provide a strong assessment of reliability for the FOODLABfat, if the obtained results (AVs and POVs in this study) from FOODLABfat were in good agreement with the official methods (ISO 660 for AV and ISO 3960 for POV in this study), independent of the fatty acid composition and saturated and/or unsaturated fatty acid content in the tested oils.

The changes in the AV and POV of the tested oils during thermally induced oxidation at $180^{\circ} \mathrm{C}$ (deep-fat frying) are presented in Tables 1 and 2 (also in Figures S2 and S3), respectively. Having established equivalence between the results from FOODLABfat and the official methods, the ability of the reagent kit based on spectrophotometry to be practically applied was tested by analyzing the rancidity in deep-fat frying oils. There were significant correlations between FOODLABfat and the official methods for typical time courses involving the initiation, propagation, and termination of lipid oxidation of edible oils. Initial AVs and POVs in all oils were significantly lower than the criteria for the oxidative stability, irrespective of tested methods, indicating that all of the oil samples were fresh and lacked oxidation products (data not shown). Heating the oils at $180^{\circ} \mathrm{C}$ for $5 \mathrm{~h}$
TABLE 1: Change in AVs of commercialized edible oils during the thermally induced oxidation at $180^{\circ} \mathrm{C}$.

\begin{tabular}{|c|c|c|c|}
\hline \multirow{2}{*}{ Item } & \multirow{2}{*}{ Incubation time $(\mathrm{h})$} & \multicolumn{2}{|c|}{ Acid value } \\
\hline & & ISO 660 & FOODLAB $f a t$ \\
\hline \multirow{6}{*}{ Canola oil } & 0 & $0.01 \pm 0.01^{\mathrm{b}}$ & $0.06 \pm 0.00^{\mathrm{a}}$ \\
\hline & 1 & $0.30 \pm 0.02^{\mathrm{a}}$ & $0.27 \pm 0.01^{\mathrm{a}}$ \\
\hline & 2 & $1.06 \pm 0.03^{\mathrm{a}}$ & $1.10 \pm 0.05^{\mathrm{a}}$ \\
\hline & 3 & $1.64 \pm 0.05^{\mathrm{a}}$ & $1.73 \pm 0.01^{\mathrm{a}}$ \\
\hline & 4 & $2.35 \pm 0.06^{\mathrm{a}}$ & $2.45 \pm 0.05^{\mathrm{a}}$ \\
\hline & 5 & $2.49 \pm 0.02^{\mathrm{a}}$ & $2.55 \pm 0.04^{\mathrm{a}}$ \\
\hline \multirow{6}{*}{ Olive oil } & 0 & $0.11 \pm 0.01^{\mathrm{a}}$ & $0.01 \pm 0.00^{\mathrm{a}}$ \\
\hline & 1 & $0.46 \pm 0.02^{\mathrm{a}}$ & $0.47 \pm 0.03^{\mathrm{a}}$ \\
\hline & 2 & $1.05 \pm 0.07^{\mathrm{a}}$ & $1.13 \pm 0.04^{\mathrm{a}}$ \\
\hline & 3 & $1.70 \pm 0.02^{\mathrm{b}}$ & $1.86 \pm 0.00^{\mathrm{a}}$ \\
\hline & 4 & $2.53 \pm 0.03^{\mathrm{a}}$ & $2.35 \pm 0.17^{\mathrm{a}}$ \\
\hline & 5 & $3.03 \pm 0.12^{b}$ & $2.60 \pm 0.19^{a}$ \\
\hline \multirow{6}{*}{ Palm oil } & 0 & $0.30 \pm 0.01^{\mathrm{b}}$ & $0.00 \pm 0.00^{\mathrm{a}}$ \\
\hline & 1 & $0.23 \pm 0.03^{\mathrm{a}}$ & $0.17 \pm 0.01^{\mathrm{a}}$ \\
\hline & 2 & $0.58 \pm 0.04^{\mathrm{a}}$ & $0.65 \pm 0.04^{\mathrm{a}}$ \\
\hline & 3 & $1.08 \pm 0.06^{\mathrm{b}}$ & $1.25 \pm 0.05^{\mathrm{a}}$ \\
\hline & 4 & $1.82 \pm 0.06^{\mathrm{a}}$ & $1.73 \pm 0.03^{\mathrm{a}}$ \\
\hline & 5 & $2.48 \pm 0.04^{\mathrm{a}}$ & $2.59 \pm 0.18^{\mathrm{a}}$ \\
\hline \multirow{6}{*}{ Soybean oil } & 0 & $0.04 \pm 0.01^{\mathrm{b}}$ & $0.06 \pm 0.00^{\mathrm{a}}$ \\
\hline & 1 & $0.22 \pm 0.02^{\mathrm{a}}$ & $0.19 \pm 0.01^{\mathrm{a}}$ \\
\hline & 2 & $0.46 \pm 0.01^{\mathrm{a}}$ & $0.47 \pm 0.01^{\mathrm{a}}$ \\
\hline & 3 & $1.01 \pm 0.02^{\mathrm{a}}$ & $1.05 \pm 0.01^{\mathrm{a}}$ \\
\hline & 4 & $1.35 \pm 0.02^{\mathrm{a}}$ & $1.37 \pm 0.01^{\mathrm{a}}$ \\
\hline & 5 & $1.75 \pm 0.02^{\mathrm{b}}$ & $1.63 \pm 0.01^{\mathrm{a}}$ \\
\hline
\end{tabular}

The values with different superscripts (a and $\mathrm{b}$ ) in each row are significantly different $(p<0.05)$.

led to a gradual and significant increase in the $\mathrm{AV}$, whereas the POV decreased after the peaking for $60 \mathrm{~min}$ in canola and olive oils and for $120 \mathrm{~min}$ in palm and soybean oils. Canola, palm, olive, and soybean oils were examined due to the high consumption of these oils worldwide. These oils also allowed us to examine the effect of fatty acid composition on the degree of deterioration during deep-fat frying.

$\mathrm{AV}$ and POV are important parameters for measuring oil quality when manufacturing deep-fat fried foods. AV is a measure of free fatty acid content and is useful for indicating the extent of oil deterioration by hydrolytic rancidity [13, 14]. During the processing of seeds or animal tissues into edible oils, the majority of the free fatty acids are removed to produce high-quality edible oils (neutralization) [15]. However, it is necessary to measure the free fatty acid levels continuously throughout oil production, storage, and distribution to ensure quality and to classify oils properly $[16,17]$. When edible oils are processed in various steps, such as deodorization, bleaching, and deep-fat frying, triacylglycerols can be hydrolyzed into free fatty acids, such as monoacylglycerols, diacylglycerols, and glycerol, which can then undergo further autooxidation [18]. High AVs found in used oils or those stored for long periods of time may indicate high levels of free fatty acids, resulting in decreased oil quality. 
TABLE 2: Change in POVs of commercialized edible oils during the thermally induced oxidation at $180^{\circ} \mathrm{C}$.

\begin{tabular}{|c|c|c|c|}
\hline \multirow{2}{*}{ Item } & \multirow{2}{*}{ Incubation time $(\mathrm{h})$} & \multicolumn{2}{|c|}{ Peroxide value } \\
\hline & & ISO 660 & FOODLAB $f a t$ \\
\hline \multirow{6}{*}{ Canola oil } & 0 & $1.60 \pm 0.03^{b}$ & $2.53 \pm 0.06^{\mathrm{a}}$ \\
\hline & 20 & $15.52 \pm 0.01^{b}$ & $18.18 \pm 0.14^{\mathrm{a}}$ \\
\hline & 40 & $25.30 \pm 0.10^{\mathrm{a}}$ & $26.22 \pm 0.50^{\mathrm{a}}$ \\
\hline & 60 & $35.15 \pm 2.29^{\mathrm{a}}$ & $35.42 \pm 0.94^{\mathrm{a}}$ \\
\hline & 120 & $31.73 \pm 1.00^{\mathrm{a}}$ & $30.54 \pm 0.78^{\mathrm{a}}$ \\
\hline & 180 & $25.52 \pm 1.26^{\mathrm{a}}$ & $24.20 \pm 1.04^{\mathrm{a}}$ \\
\hline \multirow{6}{*}{ Olive oil } & 0 & $13.00 \pm 0.64^{\mathrm{a}}$ & $14.23 \pm 0.16^{\mathrm{a}}$ \\
\hline & 20 & $24.16 \pm 0.41^{\mathrm{a}}$ & $25.42 \pm 0.97^{\mathrm{a}}$ \\
\hline & 40 & $41.24 \pm 0.64^{\mathrm{a}}$ & $41.37 \pm 0.18^{\mathrm{a}}$ \\
\hline & 60 & $49.77 \pm 1.87^{\mathrm{b}}$ & $46.92 \pm 0.67^{\mathrm{a}}$ \\
\hline & 120 & $45.73 \pm 0.97^{\mathrm{a}}$ & $43.78 \pm 0.73^{\mathrm{a}}$ \\
\hline & 180 & $42.34 \pm 1.83^{\mathrm{a}}$ & $40.45 \pm 1.05^{\mathrm{a}}$ \\
\hline \multirow{6}{*}{ Palm oil } & 0 & $1.36 \pm 0.01^{\mathrm{b}}$ & $1.88 \pm 0.03^{\mathrm{a}}$ \\
\hline & 20 & $11.76 \pm 0.63^{\mathrm{a}}$ & $14.72 \pm 1.62^{\mathrm{a}}$ \\
\hline & 40 & $20.04 \pm 0.47^{\mathrm{a}}$ & $20.50 \pm 0.44^{\mathrm{a}}$ \\
\hline & 60 & $21.19 \pm 1.69^{\mathrm{b}}$ & $23.73 \pm 0.31^{\mathrm{a}}$ \\
\hline & 120 & $33.33 \pm 0.74^{\mathrm{a}}$ & $34.84 \pm 0.73^{\mathrm{a}}$ \\
\hline & 180 & $33.17 \pm 0.32^{\mathrm{a}}$ & $31.49 \pm 0.65^{\mathrm{a}}$ \\
\hline \multirow{6}{*}{ Soybean oil } & 0 & $4.00 \pm 0.02^{\mathrm{b}}$ & $4.88 \pm 0.04^{\mathrm{a}}$ \\
\hline & 20 & $18.98 \pm 1.14^{\mathrm{b}}$ & $20.93 \pm 0.24^{\mathrm{a}}$ \\
\hline & 40 & $20.67 \pm 0.43^{\mathrm{a}}$ & $21.25 \pm 0.33^{\mathrm{a}}$ \\
\hline & 60 & $22.97 \pm 0.68^{\mathrm{a}}$ & $25.01 \pm 1.21^{\mathrm{a}}$ \\
\hline & 120 & $30.49 \pm 1.02^{\mathrm{a}}$ & $28.20 \pm 0.77^{\mathrm{a}}$ \\
\hline & 180 & $26.67 \pm 0.87^{\mathrm{a}}$ & $26.33 \pm 1.18^{\mathrm{a}}$ \\
\hline
\end{tabular}

The values with different superscripts (a and b) in each row are significantly different $(p<0.05)$.

Therefore, the AV is an important indicator for the quality assessment of edible oils.

Another important parameter is POV, which is useful for evaluating the extent of oil oxidation based on the levels of hydroperoxide, one of the primary products of oxidation [19]. When the double bonds of unsaturated fats become oxidized, peroxides are formed along with other oxidation products. The degree of oxidation can easily be determined by monitoring changes in the POV. However, in deepfat frying conditions, standard titration methods cannot differentiate between free fatty acids formed by oxidation and those by hydrolysis. Furthermore, hydroperoxides are very unstable and easily decomposed, resulting in the formation of aldehydes, ketones, and epoxides, causing the accumulation of secondary oxidation products and a decrease in POV [20]. This information suggests that either the AV or POV alone is insufficient for assessing deterioration in frying fats and oils. Therefore, both AV and POV are required to fully characterize the extent of oil deterioration in deep-fat frying, and it is recommended that frying oils with AV levels above 2.0-2.5 and/or POV levels above 30-50 milliequivalents of active oxygen per kilogram of oil $\left(\mathrm{meqO}_{2} \mathrm{~kg}^{-1}\right)$ should be discarded [21].
Several official methods have been established for determining $\mathrm{AV}$ and $\mathrm{POV}$ in fats and oils, most of which are based on titration in organic solvents. Although these official methods are widely accepted, they have numerous disadvantages, such as the need for large sample volumes and organic solvents, a relatively long time necessary to perform the procedure, incomplete solubility of fats and oils, a need to preneutralize the organic solvents, and the possibility of manual error across multiple steps $[22,23]$.

Continuous industrial fryers have been commonly used in commercial settings. In these systems, the product is fed into the fryer at one end, and the finished product is collected from the opposite end. The temperature of the frying oil is maintained at $160-180^{\circ} \mathrm{C}$, and fresh oil is periodically added to the fryer to manage oil quality. The volume of fresh oil added is determined by monitoring the changes in the AV and POV during frying. Generally, most food industries maintain oil quality at levels below 1.0 of AV and 10.0 of POV. Standard titration methods commonly used by food industries to determine AV and POV are subject to considerable error as long as manual operators are involved. Misjudging the color of the indicator near the endpoint and misreading the volume graduation marks on the burette are the most common errors in standard methods based on titration. These titration errors can significantly impact assessments of oil quality. Because of a single droplet (approximately $0.06 \mathrm{~mL}$, as the exact volume could vary due to burette outlet diameter) of titrant for AV and POV, values 0.02 and 0.1 higher for $\mathrm{AV}$ and POV could be obtained. Although it is not a type of titration error, an individual's preference for different criteria in judging the color appearance near the endpoint of titration could be the obstacle in obtaining true values of $\mathrm{AV}$ and POV. FOODLABfat produced AV and POV that have a high correlation to the results obtained from official methods, such as the ISO 660 and ISO 3960 protocols. In addition, it does not share the limitations or disadvantages of titration-based methods.

\section{Conclusions}

AVs and POVs obtained from FOODLAB $f a t$ showed good agreement with those obtained from the official methods. This analytical technique was validated to be reliable and reproducible for determining the oxidation degree of edible oils. Furthermore, it could provide many advantages compared with the official methods because of its rapidness, simplicity, and sensitivity.

\section{Competing Interests}

The authors declare that there is no conflict of interests regarding the publication of this paper.

\section{Authors' Contributions}

Chang Woo Kwon and Kyung-Min Park contributed equally to this work. Seung Jun Choi and Pahn-Shick Chang made an equal contribution as co-corresponding authors to this work. 


\section{Acknowledgments}

This study was financially supported by the Basic Science Research Program through the National Research Foundation of Korea (NRF) funded by the Ministry of Science, ICT, \& Future Planning (NRF-2013R1A1A2074378) and in part by the High Value-Added Food Technology Development Program (313021-3) of the Ministry of Agriculture, Food, and Rural Affairs, Republic of Korea.

\section{References}

[1] A. B. Falowo, P. O. Fayemi, and V. Muchenje, "Natural antioxidants against lipid-protein oxidative deterioration in meat and meat products: a review," Food Research International, vol. 64, pp. 171-181, 2014.

[2] S. Calligaris, L. Manzocco, M. Anese, and M. C. Nicoli, "Shelf-life assessment of food undergoing oxidation-a review," Critical Reviews in Food Science and Nutrition, vol. 56, no. 11, pp. 1903-1912, 2016.

[3] D. Ansorena, B. Barriuso, V. Cardenia, I. Astiasarán, G. Lercker, and M. T. Rodriguez-Estrada, "Thermo-oxidation of cholesterol: effect of the unsaturation degree of the lipid matrix," Food Chemistry, vol. 141, no. 3, pp. 2757-2764, 2013.

[4] M. Gómez, J. Vila, R. Elosua et al., "Relationship of lipid oxidation with subclinical atherosclerosis and 10-year coronary events in general population," Atherosclerosis, vol. 232, no. 1, pp. 134-140, 2014.

[5] C. C. Akoh and D. B. Min, Food Lipids: Chemistry, Nutrition, and Biotechnology, CRC press, Boca Raton, Fla, USA, 2008.

[6] E. Ronald, E. Terry, A. Eric et al., Handbook of Food Analytical Chemistry, John Wiley \& Sons, Hoboken, NJ, USA, 2005.

[7] ISO660, Animal and Vegetable Fats and Oils-Determination of Acid Value and Acidity, International Organization for Standardization, Geneva, Switzerland, 2009.

[8] ISO3960, Animal and Vegetable Fats and Oils-Determination of Peroxide Value-Iodometric (Visual) Endpoint Determination, International Organization for Standardization, Geneva, Switzerland, 2007.

[9] N. C. Shantha and E. A. Decker, "Rapid, sensitive, iron-based spectrophotometric methods for determination of peroxide values of food lipids," Journal of AOAC International, vol. 77, no. 2, pp. 421-424, 1994.

[10] V. N. Kamvissis, E. G. Barbounis, N. C. Megoulas, and M. A. Koupparis, "A novel photometric method for evaluation of the oxidative stability of virgin olive oils," Journal of AOAC International, vol. 91, no. 4, pp. 794-801, 2008.

[11] ISO3976, Milk Fat-Determination of Peroxide Value, International Organization for Standardization, Geneva, Switzerland, 2006.

[12] V. Dubois, S. Breton, M. Linder, J. Fanni, and M. Parmentier, "Fatty acid profiles of 80 vegetable oils with regard to their nutritional potential," European Journal of Lipid Science and Technology, vol. 109, no. 7, pp. 710-732, 2007.

[13] S. Naz, R. Siddiqi, H. Sheikh, and S. A. Sayeed, "Deterioration of olive, corn and soybean oils due to air, light, heat and deepfrying," Food Research International, vol. 38, no. 2, pp. 127-134, 2005.

[14] J. B. Rossell, "Industrial frying process," Grasas y Aceites, vol. 49, no. 4-5, pp. 282-295, 1998.
[15] N. A. Febrianto and T. A. Yang, "Producing high quality edible oil by using eco-friendly technology: a review," Advance Journal of Food Science and Technology, vol. 3, no. 4, pp. 317-326, 2011.

[16] M. Abdulkadir, G. Abubakar, and A. Mohammed, "Production and characterization of oil from fishes," ARPN Journal of Engineering and Applied Sciences, vol. 5, no. 7, pp. 769-776, 2010.

[17] R. Bou, J. A. Navas, A. Tres, R. Codony, and F. Guardiola, "Quality assessment of frying fats and fried snacks during continuous deep-fat frying at different large-scale producers," Food Control, vol. 27, no. 1, pp. 254-267, 2012.

[18] E. Choe and D. B. Min, "Chemistry of deep-fat frying oils," Journal of Food Science, vol. 72, no. 5, pp. R77-R86, 2007.

[19] S. G. Stevenson, M. Vaisey-Genser, and N. A. M. Eskin, "Quality control in the use of deep frying oils," Journal of the American Oil Chemists' Society, vol. 61, no. 6, pp. 1102-1108, 1984.

[20] Q. Zhang, A. S. M. Saleh, J. Chen, and Q. Shen, "Chemical alterations taken place during deep-fat frying based on certain reaction products: a review," Chemistry and Physics of Lipids, vol. 165, no. 6, pp. 662-681, 2012.

[21] G. Bansal, W. Zhou, P. J. Barlow, P. S. Joshi, H. L. Lo, and Y. K. Chung, "Review of rapid tests available for measuring the quality changes in frying oils and comparison with standard methods," Critical Reviews in Food Science and Nutrition, vol. 50, no. 6, pp. 503-514, 2010.

[22] I. Kuselman and A. Shenhar, "Uncertainty in chemical analysis and validation of the analytical method: acid value determination in oils," Accreditation and Quality Assurance, vol. 2, no. 4, pp. 180-185, 1997.

[23] I. Kuselman, E. Kardash-Strochkova, and Y. I. Tur'yan, “Uncertainty and other metrological parameters of peroxide value determination in vegetable oils," Accreditation and Quality Assurance, vol. 7, no. 1, pp. 13-18, 2002. 

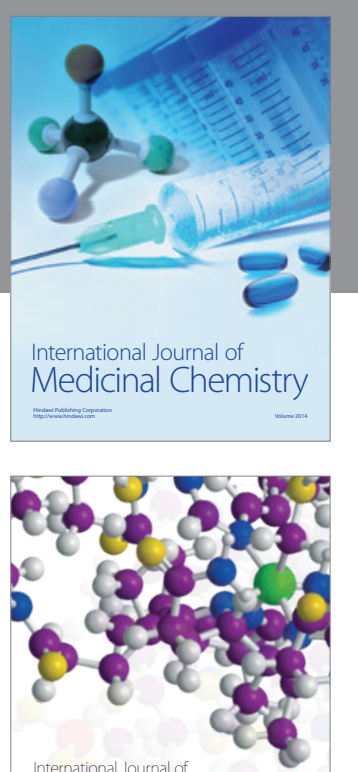

Carbohydrate Chemistry

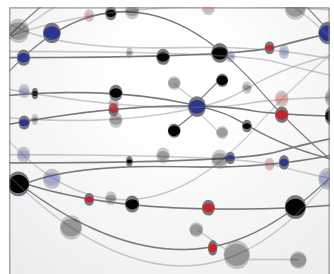

The Scientific World Journal
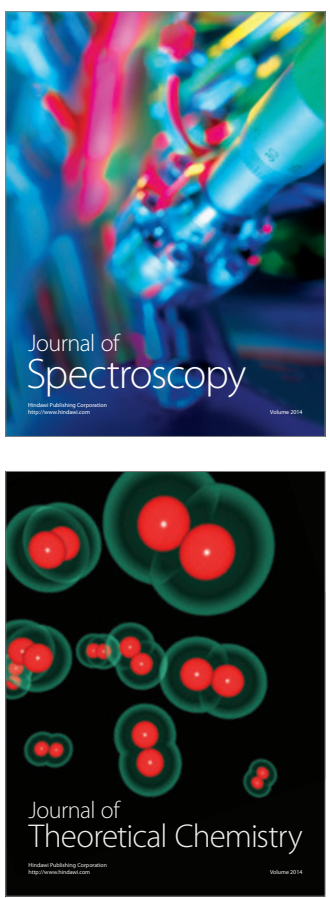
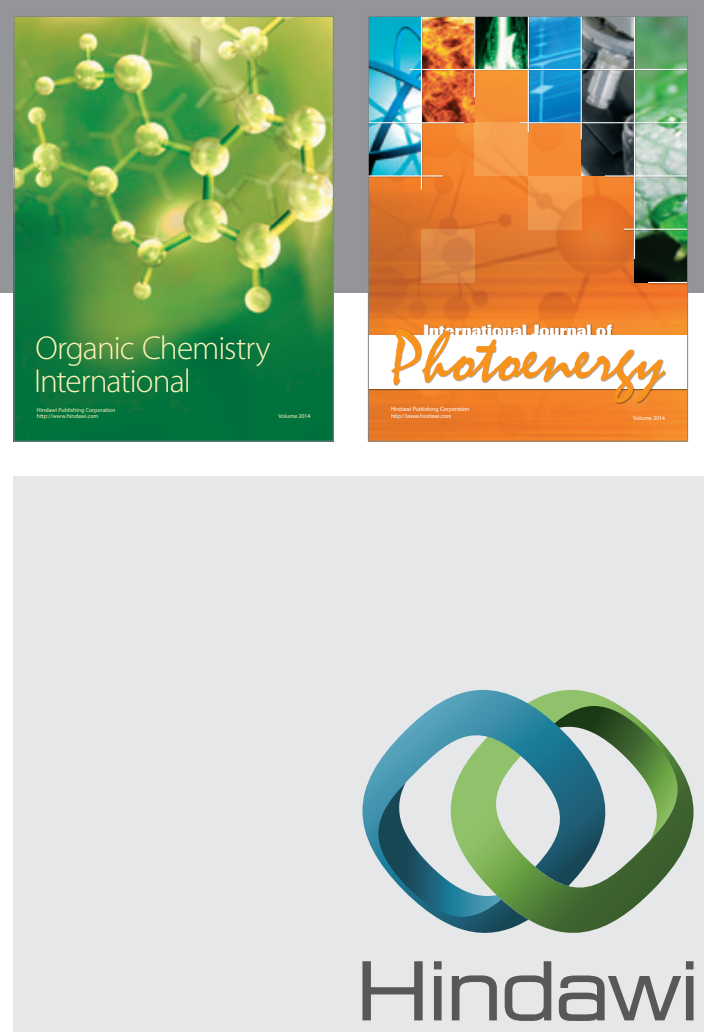

Submit your manuscripts at

http://www.hindawi.com

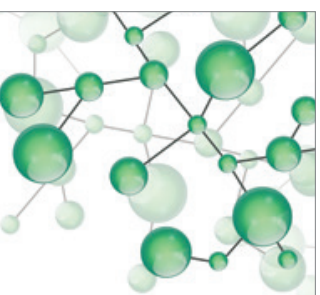

International Journal of

Inorganic Chemistry

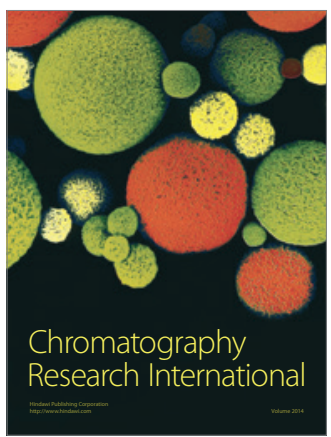

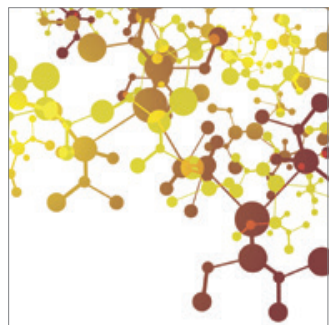

Applied Chemistry
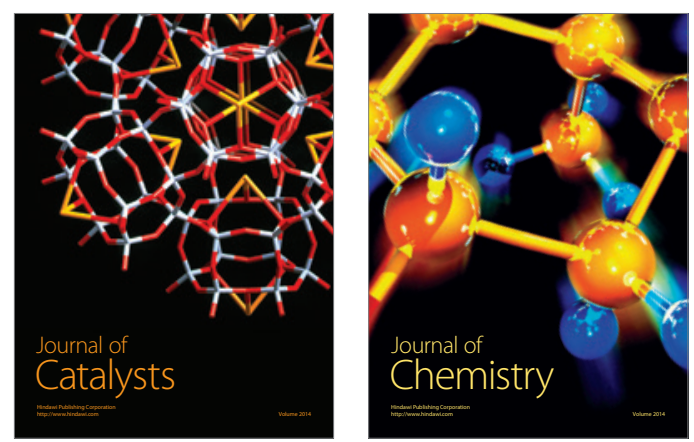
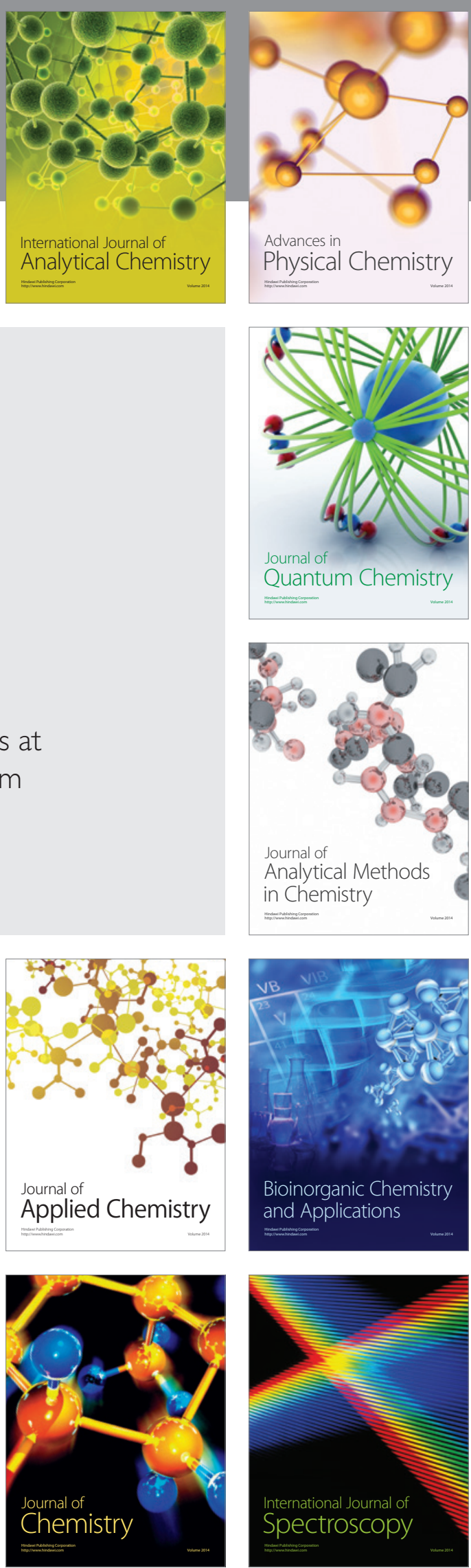